Check for updates

Cite this: RSC Adv., 2018, 8, 6910

Received 19th December 2017 Accepted 4th February 2018

DOI: $10.1039 / \mathrm{c} 7 \mathrm{ra13471a}$

rsc.li/rsc-advances

\title{
Desymmetrisation of meso-diones promoted by a highly recyclable polymer-supported chiral phosphoric acid catalyst $\uparrow$
}

\author{
Lidia Clot-Almenara, (DD a Carles Rodríguez-Escrich (D) *a and Miquel A. Pericàs (DD *ab
}

A polystyrene-supported BINOL-derived chiral phosphoric acid has been applied to the desymmetrisation of meso-diones to produce enantioenriched cyclohexenones. The catalytic resin has proven highly active and robust, giving rise to Hajos-Parrish or Wieland-Miescher type products in good yields and enantioselectivities, while allowing for extended recycling.

\section{Introduction}

The Robinson annulation represents one of the most powerful synthetic strategies for the synthesis of cyclohexenone derivatives, ${ }^{\mathbf{1}}$ which are extremely versatile building blocks for the preparation of natural products. In 1971, two industrial research groups, Hajos and Parrish ${ }^{2}$ (working at Hoffmann-La Roche) and Eder, Sauer and Weichert ${ }^{3}$ (from Schering AG), independently discovered a catalytic asymmetric variant of the Robinson annulation that was mediated by proline, in what is nowadays considered one of the most important breakthroughs in organocatalysis. ${ }^{4}$ This transformation, also known as the Hajos-Parrish-Eder-Sauer-Wiechert reaction (Scheme 1, top), has emerged as a powerful tool for the total synthesis of natural products ${ }^{5}$ and bioactive compounds, ${ }^{6}$ predominantly sesquiterpenoids, ${ }^{7}$ terpenoids ${ }^{8}$ and steroids, ${ }^{9}$ which stand out for their antimicrobial, antiviral and anticancer effect (Scheme 1, bottom).

Efforts to identify an alternative organocatalyst able to promote the asymmetric Robinson annulation include proline derivatives, ${ }^{\mathbf{1 0}}$ amines ${ }^{\mathbf{1 1}}$ amino acids,${ }^{\mathbf{1 2}}$ peptides, ${ }^{\mathbf{1 3}}$ antibodies, ${ }^{\mathbf{1 4}}$ prolinamide ${ }^{15}$ or chiral vicinal diamines. ${ }^{16}$ It is thus evident that the common motif in most of the catalytic entities employed so far is the presence of a chiral amine, which is assumed to promote the reaction through the enamine activation mode. ${ }^{\mathbf{1 7}}$ However, according to the commonly accepted mechanistic rationalisations, the presence of a base slows down the second half of the process, namely, the dehydration of the $\beta$-hydroxyketone intermediate. This step is accelerated in acidic media

${ }^{a}$ Institute of Chemical Research of Catalonia (ICIQ), The Barcelona Institute of Science and Technology, Av. Països Catalans 16,43007 Tarragona, Spain.E-mail: mapericas@ iciq.es

${ }^{b}$ Departament de Quimica Inorgànica i Orgànica, Universitat de Barcelona, 08080 Barcelona, Spain

$\dagger$ Electronic supplementary information (ESI) available: Experimental procedures, characterisation data, NMR spectra and HPLC traces. See DOI: 10.1039/c7ra13471a and high temperatures, which is why several protocols involve addition of an acid after the starting material is consumed. Actually, even Brønsted acids alone are known to promote the Robinson annulation in an efficient manner. ${ }^{1 b}$

On the basis of these precedents, Akiyama and co-workers hypothesised that chiral phosphoric acids (CPA) should be able to mediate the desymmetrisation of meso-1,3-diones in the absence of an acidic additive; indeed, the proof of concept was reported in $2009 .{ }^{18}$ In this case, in contrast to what happens in the aminocatalytic processes, the stereoselectivity was controlled via non-covalent interactions and the same catalyst promoted the desymmetrisation and the final dehydration.

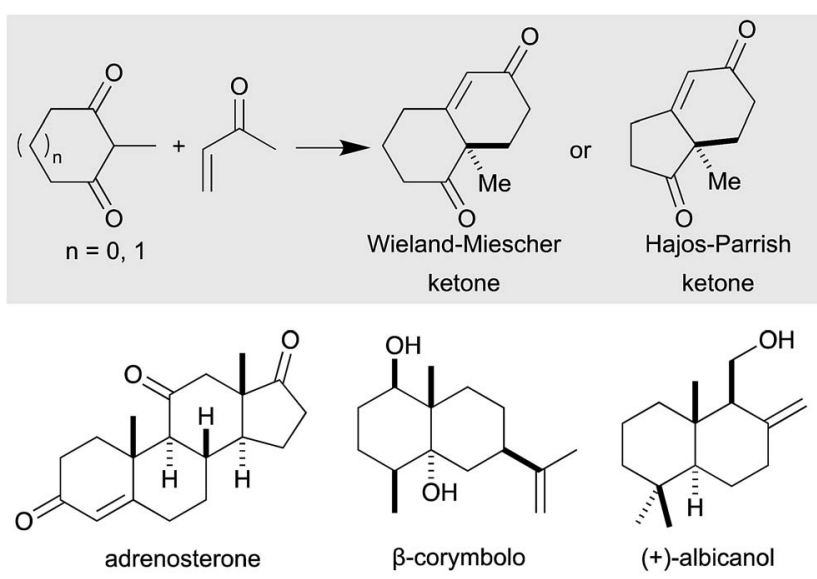

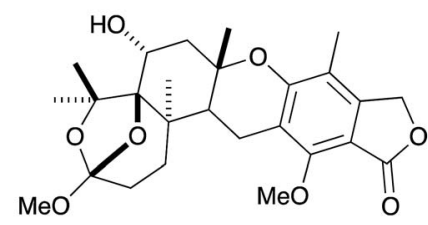

(-)-austalide B

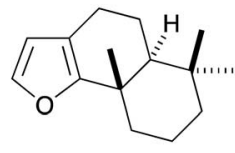

pallescensin $\mathrm{A}$
Scheme 1 Wieland-Miescher and Hajos-Parrish ketones; natural products prepared via Robinson annulation. 
Chiral phosphoric acids were independently developed in 2004 by Akiyama and Terada $^{19}$ in an attempt to harness the reactivity of imines. However, these Brønsted acid catalysts have proven to be much more versatile than initially expected, giving high levels of enantioinduction in very disparate reactions. ${ }^{20}$ Perhaps the main drawback of these CPAs is the long and tedious reaction sequences required for their preparation. In this scenario, catalyst immobilisation ${ }^{21}$ can provide a solution by rendering materials that ideally retain the properties of the monomer while being insoluble in the reaction media. With this idea in mind, several research groups, including our own, have studied the immobilisation of CPAs to assess the impact of this approach on the activity and recyclability of the resulting catalytic materials. ${ }^{22}$ Indeed, solid-supported $\mathrm{CPAs}^{23}$ turned out to be very active and robust; remarkably, in the event of loss of catalytic activity, simply washing the catalytic resin with acid restored its initial behaviour. More recently, we turned our attention to the CPA that has been more successful to date, namely, the TRIP catalyst developed by List $e t$ al. ${ }^{24}$ Thus, we prepared PS-TRIP (Fig. 1) based on a co-polymerisation strategy and applied it to the asymmetric allylboration of aldehydes. ${ }^{25}$ The catalytic resin admitted recycling in batch and the implementation of a flow process spanning $28 \mathrm{~h}$. It is worth noting that, about the same time, Kobayashi et al. reported on a very similar immobilisation strategy to obtain a hybrid material that combined supported TRIP and $\mathrm{Au} / \mathrm{Pd}$ nanoparticles. ${ }^{26}$ This heterogeneous catalyst exploited the benefits of both catalysts, allowing to carry out a sequence of oxidation and enantioselective $a z a$-Friedel-Crafts reaction.

These previous results encouraged us to tackle the applicability of the PS-TRIP catalyst to the desymmetrisation of meso1,3-diones to produce chiral cyclohexenones, with particular interest in the easy separation of final product and catalyst and the recovery of the latter. As previously mentioned, the acidic nature of the catalyst enables the application of the same reaction conditions to carry out both the desymmetrisation and the dehydration, without having to use any additive or modify the temperature. In contrast, previous attempts to apply solidsupported catalysts to promote this reaction have relied in aminocatalytic approaches involving proline or prolinamide derivatives supported on polystyrene, ${ }^{27}$ silica $^{15,28}$ or polyethyleneglycol (Fig. 2). ${ }^{29}$ More recently, the Luo diamine

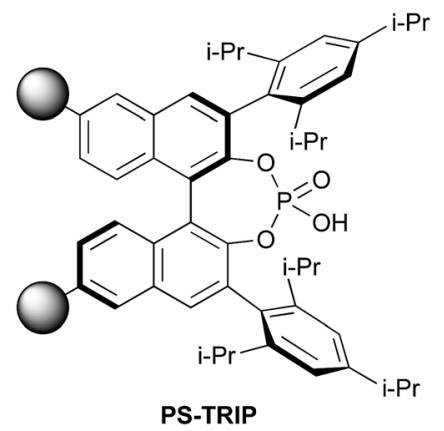

Fig. 1 Polystyrene-supported TRIP phosphoric acid catalyst.
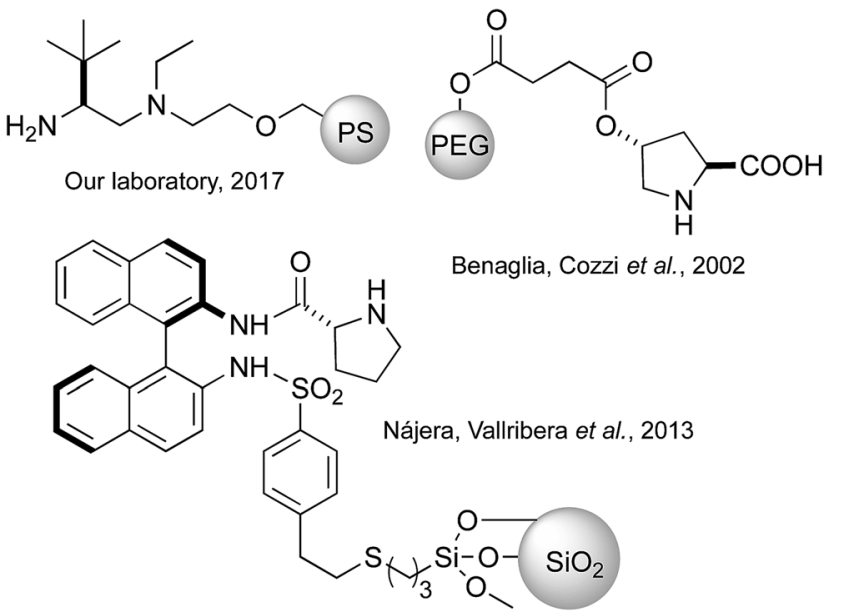

Fig. 2 Selection of previously reported immobilised catalysts for the desymmetrisation of meso-diones.

catalyst ${ }^{16}$ has been supported onto polystyrene, proving to be recyclable and allowing operation in continuous flow. ${ }^{30}$

\section{Results and discussion}

On the basis of the homogeneous precedent, ${ }^{18}$ we decided to initiate our investigation using $\mathbf{1 a}$ as a model substrate with our PS-TRIP catalyst in different solvents (Table 1, entries 1-5). As expected, almost no reactivity was observed at room temperature with the exception of toluene and hexane (35\% yield).

Table 1 Screening of reaction conditions for the desymmetrisation of meso-dione $1 a^{a}$

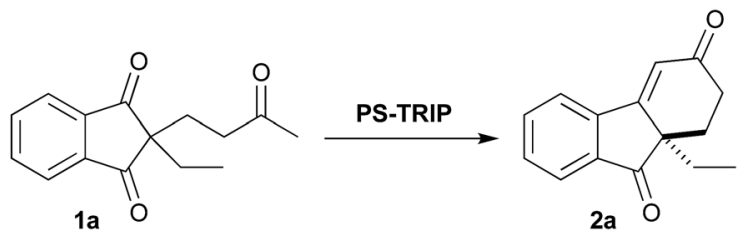

\begin{tabular}{|c|c|c|c|c|c|c|}
\hline Entry & Solvent & $\begin{array}{l}\text { Temp } \\
{\left[{ }^{\circ} \mathrm{C}\right]}\end{array}$ & $\begin{array}{l}\text { Cat. loading } \\
{[\%]}\end{array}$ & $\begin{array}{l}\text { Time } \\
{[\mathrm{h}]}\end{array}$ & $\begin{array}{l}\text { Yield }^{b} \\
{[\%]}\end{array}$ & $\begin{array}{l}\mathrm{ee}^{c} \\
{[\%]}\end{array}$ \\
\hline 1 & Hexane & $\mathrm{rt}$ & 5 & 32 & 35 & 90 \\
\hline 2 & EtOAc & $\mathrm{rt}$ & 5 & 32 & - & - \\
\hline 3 & $\mathrm{CH}_{2} \mathrm{Cl}_{2}$ & $\mathrm{rt}$ & 5 & 32 & - & - \\
\hline 4 & THF & $\mathrm{rt}$ & 5 & 32 & - & - \\
\hline 5 & Toluene & $\mathrm{rt}$ & 5 & 32 & Traces & - \\
\hline 6 & Hexane & 70 & 5 & 48 & 50 & 91 \\
\hline 7 & Hexane & 70 & 10 & 24 & 80 & 89 \\
\hline 8 & DCE & 70 & 10 & 24 & 64 & 90 \\
\hline 9 & Hexane & 70 & 10 & 24 & 75 & 88 \\
\hline 10 & Hexane & 70 & 15 & 24 & 64 & 88 \\
\hline 11 & Hexane & 70 & 20 & 24 & 69 & 88 \\
\hline 12 & Hexane & 70 & 20 & 48 & 98 & 89 \\
\hline
\end{tabular}

${ }^{a}$ Reactions were carried out with $0.2 \mathrm{mmol}$ of $1 \mathrm{a}$ in $2 \mathrm{~mL}$ of solvent. ${ }^{b}$ Yield of isolated product. ${ }^{c}$ Determined by HPLC on a chiral stationary phase. 
Heating up the reaction mixture to $70{ }^{\circ} \mathrm{C}$ effectively increased the yield while maintaining high enantioselectivities (entry 6). Increasing the catalyst loading to $10 \mathrm{~mol} \%$, higher yields were achieved (entry 7 ). After these preliminary results, we decided to expand the solvent screening (entries 8-9), but toluene and DCE did not improve the results observed with hexane. Finally, we increased the catalyst loading and the reaction time (entries 10-12), establishing the optimised reaction conditions to obtain the cyclohexenone product as follows: $20 \mathrm{~mol} \%$ catalyst, $70{ }^{\circ} \mathrm{C}$ and $48 \mathrm{~h}$ (98\% yield, 89\% ee).

With the optimised conditions in hand, we moved to explore the reaction scope, starting with the benzo-fused meso-diones (Scheme 2). The methyl-substituted analogue $\mathbf{2 b}$ was obtained in excellent yield and enantioselectivity (94\%, 88\% ee).

The compound bearing a phenyl group gave moderate yields, which can be attributed to the low solubility of the starting material. Indeed, when the reaction was carried out in toluene at $90{ }^{\circ} \mathrm{C}, 2 \mathrm{c}$ was obtained in good yields. In comparison, the benzyl-substituted compound gave rise to the cyclohexenone $\mathbf{2 d}$ in considerably higher yields. As for the propargylic substrate, it displayed an excellent behaviour, furnishing 2e (an intermediate used in the synthesis of a gibbane framework ${ }^{2 d}$ ) in excellent yield and ee. In general, we can say that this type of substrates give rise to the desired cyclohexenones in very good yields and enantioselectivities, despite the somewhat elevated reaction temperatures employed.

The results obtained with meso-diones 3, lacking the fused benzene ring, are summarised in Scheme 3; in this case the results were not as good as those recorded for the tricyclic compounds. For instance, the Hajos-Parrish 4a and
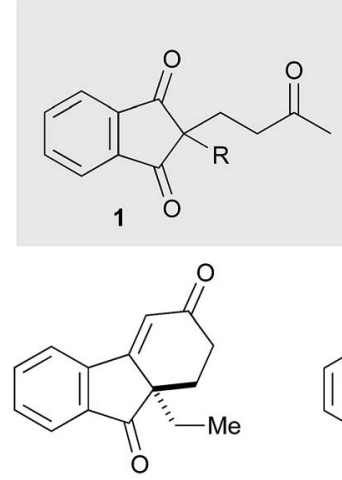

$2 a$ $98 \%-89 \%$ ee
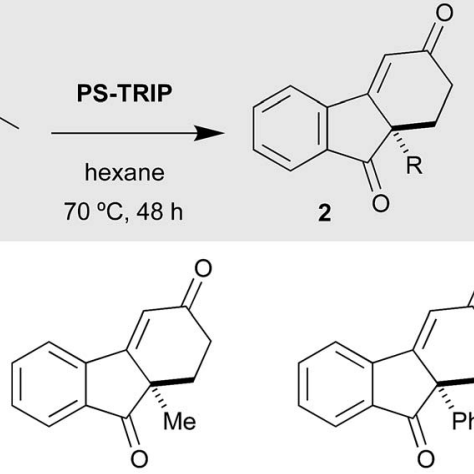
$94 \%-88 \%$ ee

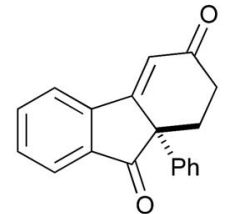

$2 c^{b}$<smiles>O=C1C=C2c3ccccc3C(=O)[C@]2(Cc2ccccc2)CC1</smiles>

2d

$91 \%-84 \%$ ee

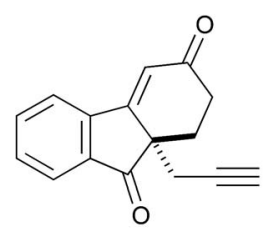

$2 \mathrm{e}$

$96 \%-92 \%$ ee

Scheme 2 Scope of the desymmetrisation reaction with benzenefused meso-diones $1 .^{\text {a a }}$ Unless otherwise stated, the reactions were carried out with $0.12 \mathrm{mmol}$ of $1,20 \mathrm{~mol} \%$ of PS-TRIP in $1.2 \mathrm{~mL}$ of hexane. ${ }^{\mathrm{b}}$ In toluene at $90^{\circ} \mathrm{C}$.

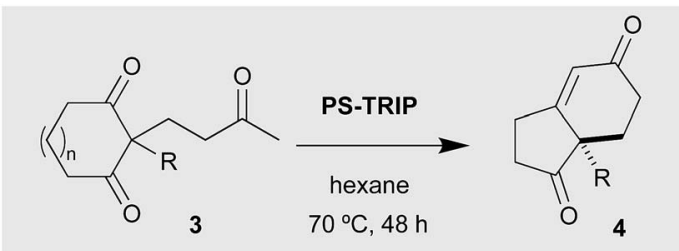

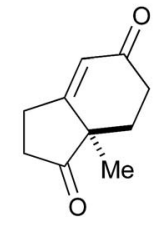

$4 a$

$79 \%-59 \%$ ee

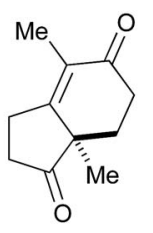

4c

$68 \%-47 \%$ ee

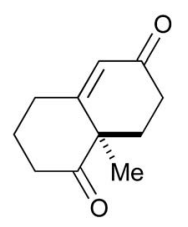

$4 b$

$60 \%-73 \%$ ee

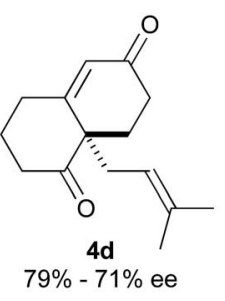

Scheme 3 Scope of the desymmetrisation reaction with cyclic mesodiones 3. a a Reactions were carried out with $0.12 \mathrm{mmol}$ of 3, $20 \mathrm{~mol} \%$ of PS-TRIP in $1.2 \mathrm{~mL}$ of hexane.

Wieland-Miescher $\mathbf{4 b}$ ketones were synthesised in decent yields but moderate ee's. Our PS-TRIP catalyst was also able to give rise to $4 \mathrm{c}$, bearing a tetrasubstituted alkene moiety, in $68 \%$ yield, but unfortunately in low enantioselectivity. Higher yield was observed in the case of the synthesis of Wieland-Miescher ketone derivative $\mathbf{4 d}$, bearing the classical dimethylallyl group present in many terpene derivatives.

The PS-TRIP resin has shown not only to be active in a wide variety of substrates, but also to be highly recyclable. Remarkably, all substrates have been run with two samples of polymer, which were already employed in the screening table. Accordingly, each sample of catalyst has been used 9 times in total without appreciable decay in activity. After each run, the catalyst was rinsed, dried in the vacuum line overnight and reused again without further reconditioning. Considering the multi-step, tedious preparation of the TRIP catalyst, this feature allows saving huge amounts of solvent and chemical waste, thus contributing to the greenness of the overall process.

\section{Conclusions}

In summary, we have established an efficient strategy for the desymmetrisation of meso-1,3-diones catalysed by an immobilised version of the TRIP phosphoric acid catalyst. This approach can be applied to a broad range of starting mesodiones, giving rise to the corresponding cyclised products in up to $98 \%$ yield and $92 \%$ enantiomeric excess. In this work, we also demonstrate the efficiency of the PS-TRIP catalyst, which is easily recovered by simple filtration and reused at least nine times, thus facilitating the isolation of the final product. 


\section{Conflicts of interest}

There are no conflicts to declare.

\section{Acknowledgements}

Financial support from CERCA Programme/Generalitat de Catalunya, MINECO (CTQ2015-69136-R, AEI/MINECO/FEDER, UE, Severo Ochoa Excellence Accreditation 2014-2018, SEV2013-0319 and FPI predoctoral grant to L. C.-A.) and AGAURGeneralitat de Catalunya (Grant 2014SGR827) is acknowledged.

\section{Notes and references}

1 (a) W. S. Rapson and R. Robinson, J. Chem. Soc., 1935, 12851288; (b) C. H. Heathcock, J. E. Ellis, J. E. McMurry and A. Coppolino, Tetrahedron Lett., 1971, 12, 4995-4996; (c) R. E. Gawley, Synthesis, 1976, 777-794.

2 (a) Z. G. Hajos and D. R. Parrish, German patent DE 2102623, 1971; (b) Z. G. Hajos and D. R. Parrish, J. Org. Chem., 1974, 39, 1615-1621; (c) R. A. Micheli, Z. G. Hajos, N. Cohen, D. R. Parrish, L. A. Portland, W. Sciamanna, M. A. Scott and P. A. Wehrli, J. Org. Chem., 1975, 40, 675-681; (d) S. Takano, C. Kasahara and K. Ogasawara, J. Chem. Soc., Chem. Commun., 1981, 635-637.

3 (a) U. Eder, G. R. Sauer and R. Wiechert, German patent DE 2014757, 1971; (b) U. Eder, G. Sauer and R. Wiechert, Angew. Chem., Int. Ed., 1971, 10, 496-497; (c) J. Gutzwiller, P. Buchschacher and A. Früst, Synthesis, 1977, 167-168.

4 For a historical essay, see: C. F. Barbas, Angew. Chem., Int. Ed., 2008, 47, 42-47.

5 (a) J. E. McMurry and S. J. Isser, J. Am. Chem. Soc., 1972, 94, 7132-7137; (b) A. B. Smith and R. Mewshaw, J. Org. Chem., 1984, 49, 3685-3689; (c) P. A. Grieco, J. L. Collins, E. D. Moher, T. J. Fleck and R. S. Gross, J. Am. Chem. Soc., 1993, 115, 6078-6093; (d) L. A. Paquette, T.-Z. Wang and M. R. Sivik, J. Am. Chem. Soc., 1994, 116, 11323-11334; (e) X.-P. Zeng, Z.-Y. Cao, Y.-H. Wang, F. Zhou and J. Zhou, Chem. Rev., 2016, 116, 7330-7396.

6 (a) E. J. Cragoe, O. W. Woltersdorf, N. P. Gould, A. M. Pietruszkiewicz, C. Ziegler, Y. Sakurai, G. E. Stokker, P. S. Anderson and R. S. Bourke, J. Med. Chem., 1986, 29, 825-841; (b) R. C. A. Isaacs, M. J. Di Grandi and S. J. Danishefsky, J. Org. Chem., 1993, 58, 3938-3941; (c) S. Yamashita, K. Iso and M. Hirama, Org. Lett., 2008, 10, 3413-3415.

7 (a) E. J. Corey, M. Ohno, R. B. Mitra and P. A. Vatakencherry, J. Am. Chem. Soc., 1964, 86, 478-485; (b) H. M. C. Ferraz, A. J. C. Souza, B. S. M. Tenius and G. G. Bianco, Tetrahedron, 2006, 62, 9232-9236.

8 T. J. Reddy, G. Bordeau and L. Trimble, Org. Lett., 2006, 8, 5585-5588.

9 C. D. Dzierba, K. S. Zandi, T. Möllers and K. J. Shea, J. Am. Chem. Soc., 1996, 118, 4711-4712.

10 (a) P. H.-Y. Cheong, K. N. Houk, J. S. Warrier and S. Hanessian, Adv. Synth. Catal., 2004, 346, 1111-1115; (b) P. H.-Y. Cheong and K. N. Houk, Synthesis, 2005, 1533-
1537; (c) E. Lacoste, E. Vaique, M. Berlande, I. Pianet, J.-M. Vincent and Y. Landais, Eur. J. Org. Chem., 2007, 167177.

11 (a) T. Kanger, K. Kriis, M. Laars, T. Kailas, A.-M. Müürisepp, T. Pehk and M. Lopp, J. Org. Chem., 2007, 72, 5168-5173; (b) M. Laars, K. Kriis, T. Kailas, A.-M. Müürisepp, T. Pehk, T. Kanger and M. Lopp, Tetrahedron: Asymmetry, 2008, 19, 641-645; (c) Á. L. Fuentes de Arriba, D. G. Seisdedos, L. Simón, V. Alcázar, C. Raposo and J. R. Morán, J. Org. Chem., 2010, 75, 8303-8306.

12 (a) T. Wakabayashi, K. Watanabe and Y. Kato, Synth. Commun., 1977, 7, 239-244; (b) S. G. Davies, R. L. Sheppard, A. D. Smith and J. E. Thomson, Chem. Commun., 2005, 41, 3802-3804; (c) S. G. Davies, A. J. Russell, R. L. Sheppard, A. D. Smith and J. E. Thomson, Org. Biomol. Chem., 2007, 5, 3190-3200.

13 V. D'Elia, H. Zwicknagl and O. Reiser, J. Org. Chem., 2008, 73, 3262-3265.

14 G. Zhong, T. Hoffmann, R. A. Lerner, S. Danishefsky and C. F. Barbas, J. Am. Chem. Soc., 1997, 119, 8131-8132.

15 A. Monge-Marcet, R. Pleixats, X. Cattoen, M. W. C. Man, D. A. Alonso and C. Najera, New J. Chem., 2011, 35, 27662772.

16 (a) P. Zhou, L. Zhang, S. Luo and J.-P. Cheng, J. Org. Chem., 2012, 77, 2526-2530; (b) C. Xu, L. Zhang, P. Zhou, S. Luo and J.-P. Cheng, Synthesis, 2013, 45, 1939-1945.

17 (a) B. List, Acc. Chem. Res., 2004, 37, 548-557; (b) S. Mukherjee, J. W. Yang, S. Hoffmann and B. List, Chem. Rev., 2007, 107, 5471-5569.

18 K. Mori, T. Katoh, T. Suzuki, T. Noji, M. Yamanaka and T. Akiyama, Angew. Chem., Int. Ed., 2009, 48, 9652-9654.

19 (a) T. Akiyama, J. Itoh, K. Yokota and K. Fuchibe, Angew. Chem., Int. Ed., 2004, 43, 1566-1568; (b) D. Uraguchi and M. Terada, J. Am. Chem. Soc., 2004, 126, 5356-5357.

20 For reviews on chiral Brønsted acid catalysis, see: (a) T. Akiyama, J. Itoh and K. Fuchibe, Adv. Synth. Catal., 2006, 348, 999-1010; (b) M. Rueping, A. Kuenkel and I. Atodiresei, Chem. Soc. Rev., 2011, 40, 4539-4549; (c) F. Lv, S. Liu and W. Hu, Asian J. Org. Chem., 2013, 2, 824836; (d) D. Parmar, E. Sugiono, S. Raja and M. Rueping, Chem. Rev., 2014, 114, 9047-9153.

21 For reviews on (chiral) catalyst immobilisation, see: (a) D. E. De Vos, I. F. J. Vankelecom and P. A. Jacobs, Chiral Catalyst Immobilisation and Recycling, Wiley-VCH, Weinheim, 2000; (b) M. Benaglia, Recoverable and Recyclable Catalysts, Wiley-VCH, Weinheim, 2009; (c) F. Cozzi, Adv. Synth. Catal., 2006, 348, 1367-1390; (d) A. Corma and H. Garcia, Adv. Synth. Catal., 2006, 348, 1391-1412; (e) M. Benaglia, New J. Chem., 2006, 30, 15251533; (f) M. Gruttadauria, F. Giacalone and R. Noto, Chem. Soc. Rev., 2008, 37, 1666-1688; (g) A. F. Trindade, P. M. P. Gois and C. A. M. Afonso, Chem. Rev., 2009, 109, 418-514; (h) J. Lu and P. H. Toy, Chem. Rev., 2009, 109, 815-838; (i) T. E. Kristensen and T. Hansen, Eur. J. Org. Chem., 2010, 3179-3204; (j) A. Zamboulis, N. Moitra, J. J. E. Moreau, X. Cattoën and M. Wong Chi Man, J. Mater. Chem., 2010, 20, 9322-9338. 
22 (a) M. Rueping, E. Sugiono, A. Steck and T. Theissmann, Adv. Synth. Catal., 2010, 352, 281-287; (b) C. Bleschke, J. Schmidt, D. S. Kundu, S. Blechert and A. Thomas, Adv. Synth. Catal., 2011, 353, 3101-3106; (c) D. S. Kundu, J. Schmidt, C. Bleschke, A. Thomas and S. Blechert, Angew. Chem., Int. Ed., 2012, 51, 5456-5459; (d) L. Osorio-Planes, C. Rodríguez-Escrich and M. A. Pericàs, Chem.-Eur. J., 2014, 20, 2367-2372.

23 For reviews on solid-supported, chiral Brønsted acid catalysts, see: (a) A. K. Mutyala and N. T. Patil, Org. Chem. Front., 2014, 1, 582-586; (b) C. Rodríguez-Escrich, Chim. Oggi, 2015, 33, 12-15.

24 (a) S. Hoffmann, A. M. Seayad and B. List, Angew. Chem., Int. Ed., 2005, 44, 7424-7427; (b) G. Adair, S. Mukherjee and B. List, Aldrichimica Acta, 2008, 41, 31-39; (c) M. Klussmann, L. Ratjen, S. Hoffmann, V. Wakchaure, R. Goddard and B. List, Synlett, 2010, 2189-2192.
25 L. Clot-Almenara, C. Rodríguez-Escrich, L. Osorio-Planes and M. A. Pericàs, ACS Catal., 2016, 6, 7647-7651.

26 H.-G. Cheng, J. Miguelez, H. Miyamura, W.-J. Yoo and S. Kobayashi, Chem. Sci., 2017, 8, 1356-1359.

27 (a) K. Kondo, T. Yamano and K. Takemoto, Makromol. Chem., 1985, 186, 1781-1785; (b) R. Pedrosa, J. M. Andrés, R. Manzano and C. Pérez-López, Tetrahedron Lett., 2013, 54, 3101-3104.

28 (a) A. Monge-Marcet, X. Cattoen, D. A. Alonso, C. Najera, M. W. C. Man and R. Pleixats, Green Chem., 2012, 14, 1601-1610; (b) A. Bañón-Caballero, G. Guillena, C. Nájera, E. Faggi, R. M. Sebastián and A. Vallribera, Tetrahedron, 2013, 69, 1307-1315.

29 M. Benaglia, M. Cinquini, F. Cozzi, A. Puglisi and G. Celentano, Adv. Synth. Catal., 2002, 344, 533-542.

30 S. Cañellas, C. Ayats, A. H. Henseler and M. A. Pericàs, ACS Catal., 2017, 7, 1383-1391. 